\title{
Factors associated with nonalcoholic fatty liver disease grades detected by ultrasound at a screening center in Klang Valley, Malaysia.
}

\author{
Abdul Sattar A. Khammas* \\ Safwan S. Mohammed* \\ Hasyma Abu Hassan** \\ Hayati k. Shahar**** \\ Ramlah M. Ibrahim***** \\ Nurul N. Mohamad Nasir**** \\ Sarah Q. M. Salih****** \\ Rozi Mahmud*******
}
MSc
CABR
PhD
PhD
MSc
MSc
MSc
PhD

JFac Med Baghdad 2018; Vol.60, No.1 Received Dec. 2017 Accepted Mar. 2018

Background: Non-alcoholic fatty liver disease (NAFLD) is a very common liver disease in the world, particularly in Western and developed countries. It is rapidly growing in the Asia- Pacific region.

Objectives: This study was designed to determine the association between risk factors and nonalcoholic fatty liver disease grades among Malaysian adults.

Patients and Methods: A cross-sectional observational study design was prospectively carried out in this study. Consecutive 628 respondents who attended for a medical checkup at urban health center had been recruited for the study. All respondents had physical examination, blood tests, clinical assessments and abdominal ultrasound. A structured self-administered questionnaire has been also used in this study in this survey.

Results: From total of 628 "health screened" subjects, 235 subjects (37.4\%) were diagnosed to have non-alcoholic fatty liver disease. Female gender and Chinese race were predominant in our study population. Of those with NAFLD, more than half subjects (63.4) had a moderate grade of nonalcoholic fatty liver disease. The mean age of the study population was $54.54 \pm 6.69$ years. Differences of mean body mass index (BMI) and waist to hip ratio (WHR) were found to be significant among nonalcoholic fatty liver disease grades $(P<0.001)$. Similarly, mean triglycerides (TG) and high-densiy lipoprotein-cholesterol (HDL-C) levels had significant differences among non-alcoholic fatty liver disease grades $(P<0.001$ and $P=0.016$, respectively).

Conclusion: non-alcoholic fatty liver disease is common among urban Malaysian adult population. Anthropometric measurements were a closely correlated with non-alcoholic fatty liver disease grades.

Keywords: Non-alcoholic fatty liver disease, NAFLD grades, sonography, urban population.

Introduction:

Non-alcoholic fatty liver disease (NAFLD) is the most common chronic liver disease worldwide 1. It has been increasingly common in line with

*Dept. of Radiological Techniques, College of Medical and Health Technology/ Baghdad, University of Middle Technical alazawi.2014@hotmail.com

**Dept. of Imaging, Faculty of Medicine and Health Sciences, University of Putra Malaysia.

*** Dept. of Public Health, Faculty of Medicine and Health Sciences, University of Putra Malaysia.

**** Dept. of Nutrition and Dietetics, Faculty of Medicine and Health Sciences, University of Putra Malaysia

****** Computer Center, College of Medical and Health Technology/ Baghdad, University of Middle Technical

****** Cancer Resource and Education Centre (CaRE), Faculty of Medicine and Health Sciences, University of Putra Malaysia. increasing prevalence of obesity and other conditions of the metabolic syndrome 2,3. Histologically, NAFLD reprsents a wide spectrum of liver diseases ranging from simple steatosis (pure fatty infiltration) to non-alcoholic steatohepatitis (necroinflammatory with hepatocellular ballooning) that leads to fibrosis, cirrhosis and eventually hepatocellular carcinoma (HCC) 4,5,6. Furthermore, NAFLD is histologically similar to alcoholic fatty liver but without excessive alcohol intake 7,8 . In Western countries, up to $40 \%$ of the general adult population have NAFLD9, and overwhelmingly of them were inactive lifestyle and high-fat diets 1 . In Asia-pacific region, NAFLD was initially uncommon but recently it has been found to affect up to $30 \%$ of the general population 10. In Malaysia, where prevalence of obesity and diabetes mellitus (DM) have been reported to be on the increase 11, the prevalence of NAFLD would be alarmingly among Malaysian population as well.

Ultrasound was widely used as a non-invasive tool for diagnosis NAFLD and its grades with sensitivity 
and specificity of $60-94 \%$ and $66-95 \%$, respectively 12. Three various grades (I, II and III) of NAFLD are detected sonographically based on qualitative analysis of hepatic parenchymal echogenicity.

\section{Patients and Methods:}

A prospective cross-sectional observational study design was carried out among patients with age ranges between 45 and 75 years, who underwent a screening program for the period from 15th August, 2015 to 15 th January, 2016 at the Golden Horses Health Sanctuary (GHHS) located in Selangor, Malaysia. This center serves medical screening and checkup health programs for subjects who live in this area. The majority of the subjects who attend this center belong to the major races in Malaysian, which are Malays, Chinese and Indians. Medical checkups carried out in this center include consultation with blood tests, physical examination, abdominal and breast sonography as well as computerized tomography (CT) scanning.

Instruments of the study: Ultrasound and selfadministered questionnaire were set as instruments in this study as following:

Ultrasonography: Ultrasound machine (Philips medium range/ $\mathrm{HD}$ 15) equipped with $3.5 \mathrm{MHz}$ probe was used for screening subjects in this study. Ultrasound examination was achieved on each subject by radiologist with experience more than ten years. NAFLD was detected on the basis of two of the following criteria: increasing liver echogenicity (bright liver) compared with right renal cortex and spleen, loss visualization of intrahepatic vessels walls as well as posterior attenuation of the ultrasound beam13. Ultrasonography was used to diagnose fatty liver grades as follows 14, 15, 16:

When there is slight increase in liver echogenicity, it is described as grade I or mild.

When there is clear increase in liver echogenicity with loss visibility of portal vein branches walls, it is described as grade II or moderate

When visualization of diaphragm and posterior portion of right lobe of liver is poor or lost, it is described as grade III or severe.

$\begin{array}{lll}\text { Self-administered questionnaire: } & \text { On self- } \\ \text { administered } & \text { questionnaire, } & \text { respondents' }\end{array}$ information such as demographic data, amount of alcoholic intake, history of the liver disease and history of medical diseases were recorded. However, lipid profile data and anthropometric measurements such as body mass index (BMI) and waist to hip ratio (WHR) were collected based on subjects' medical records. According to guidelines for the assessment and management of NAFLD in AsiaPacific region13, the men who consumed alcohol in over than $140 \mathrm{~g} /$ week and women who consumed over than $70 \mathrm{~g} /$ week, subjects with hepatitis B or C viruses, hepatotoxicity and surgery (liver transplantation surgery), and those who had taken lipid lowering medications were excluded from the study. Patient considered as having diabetes and hypertension, if they have been taking diabetes and hypertensive medications. Dietary pattern for respondents were evaluated based on semi-food frequency questionnaire (SFFQ) which has been developed and validated for Malaysian food intake by Shahril and his colleagues 17 . Moreover, physical activity questionnaire was adopted from International Physical Activity Questionnaire-short form (IPAQ, 2002) 18, which was validated to be used among adults by Booth and his colleagues (2003) 19. Subjects were asked to sign consent form before starting to fill up the questionnaire. Finally, ethical approval was obtained from JKEUPM (Ethic Committee for Research Involving Human Subject) to carry out the present study.

Classification of Lipid Profile : The cut-off values of lipid profile variables are defined according to National Cholesterol Education Program (NCEP, 2002) 20 as follows:

High-density lipoprotein-cholesterol (HDL-C) is considered low if its value $<1.04 \mathrm{mmol} / \mathrm{L}$ for men and $1.30 \mathrm{mmol} / \mathrm{L}$ for women

Triglyceride (TG) is considered high if its level $\geq$ $1.70 \mathrm{mmol} / \mathrm{L}$

Optimal value of low-density lipoprotein-cholesterol (LDL-C) is $<2.59 \mathrm{mmol} / \mathrm{L}$

Optimal value of total cholesterol (TC) is $<5.18$ $\mathrm{mmol} / \mathrm{L}$.

Data analysis: Data analysis was performed using Statistical Package for Social Science (SPSS) program version 22.0. First, descriptive analysis was carried out to calculate the percentages and means of each factor among study population. Chi-square test was performed for the association between categorical variables. Besides that, analysis of variance (ANOVA) was achieved to compare between means of more than two groups with normally distributed data. A $P$-value of less than 0.05 was considered statistically significant.

\section{Results}

Population characteristics: The characteristics of study population were shown in Table 1. A total of 628 subjects were recruited and included in the analysis. The number of subjects who recorded with NAFLD was 235 (37.4\%), whilst 393 (62.6\%) subjects without NAFLD. The study population was predominantly female and overwhelmingly Chinese in race reflecting the community from which it is derived from. The mean age of the study population was $54.54 \pm 6.69$ years. For further subanalysis, the mean age for males was $55.59 \pm 6.91$ years and for females was $53.57 \pm 6.31$ years. Three various grades (I, II and III) of the NAFLD were reported with 60 patients $(25.5 \%)$ for grade I (mild), 149 patients (63.4\%) for grade II (moderate) and 26 patients (11.1\%) for grade III (severe).

Factors associated with NAFLD grades

As shown in Table 2, there were no significant differences of age, gender and race with NAFLD grades $(P$-values were $0.957,0.432$ and 0.974 , respectively). In term of anthropometric measurements, significant differences of BMI and 
WHR among NAFLD grades have been identified $(P$-values for both were $<0.001)$. For dietary pattern, the differences of daily total calorie intake among NAFLD grades were not found to be significant $(P=0.297)$, as such; the differences of protein, fat and carbohydrate intake among NAFLD grades were also not found to be significant $(P$ values were $0.635,0.328$ and 0.403 , respectively). Moreover, our results revealed that physical activity also was not significantly associated with NAFLD grades $(P=0.311)$.

For lipid profile, mean TG was progressively increased with fatty severity where mean TG was $1.44 \pm 0.49 \mathrm{mmol} / \mathrm{L}$ among grade $\mathrm{I}, 1.71 \pm 0.73$ $\mathrm{mmol} / \mathrm{L}$ among grade II and $2.46 \pm 1.17 \mathrm{mmol} / \mathrm{L}$ among grade III. This indicates that differences of means TG among NAFLD grades were significant $(P$-value $<0.001$, respectively). Similarly, HDL-C was also gradually increased with fatty severity where mean HDL-C was $1.40 \pm 0.30 \mathrm{mmol} / \mathrm{L}$ among grade $\mathrm{I}, 1.31 \pm 0.30 \mathrm{mmol} / \mathrm{L}$ among grade $\mathrm{II}$ and 1.21 $\pm 0.21 \mathrm{mmol} / \mathrm{L}$ among grade III. This also indicates that differences of mean HDL-C among NAFLD grades were significant $P$-value $=0.016$ ).

In contrast, there were no significant differences of means TC and LDL-C among NAFLD grades $(P$ value for both variables were less than 0.05 ) (Table 2). Likewise, there was also no significant association of DM $(P$-value $=0.313)$ and hypertension $(P$-value $=0.553)$ with NAFLD grades.

\section{The characteristics of study population $(n=628)$}

Table 1

\begin{tabular}{|c|c|c|}
\hline Variables & $\mathrm{n}(\%)$ & mean $\pm \mathrm{SD}^{*}$ \\
\hline Age & - & $54.54 \pm 6.69$ \\
\hline \multicolumn{3}{|l|}{ Gender } \\
\hline Male & $302(48.1)$ & - \\
\hline Female & $326(51.9)$ & - \\
\hline \multicolumn{3}{|l|}{ Race } \\
\hline Malay & $92(14.6)$ & - \\
\hline Chinese & $518(82.5)$ & - \\
\hline Indian & $18(2.9)$ & - \\
\hline BMI** & & $24.7 \pm 4.0$ \\
\hline WHR** & & $1.1 \pm 3.6$ \\
\hline \multicolumn{3}{|l|}{ Lipid profile } \\
\hline $\mathrm{TC}^{* *}$ & - & $5.67 \pm 1.01$ \\
\hline $\mathrm{TG}^{* *}$ & - & $1.44 \pm 0.75$ \\
\hline HDL-C** & - & $1.49 \pm 0.37$ \\
\hline LDL-C** & - & $3.54 \pm 0.88$ \\
\hline \multicolumn{3}{|l|}{ DM** } \\
\hline Present & $30(4.8)$ & - \\
\hline Absent & $598(95.2)$ & - \\
\hline \multicolumn{3}{|l|}{ Hypertension } \\
\hline Present & $100(15.9)$ & - \\
\hline Absent & $528(84.1)$ & - \\
\hline \multicolumn{3}{|l|}{ NAFLD** } \\
\hline Yes & $235(37.4)$ & - \\
\hline No & $393(62.6)$ & - \\
\hline \multicolumn{3}{|l|}{ NAFLD grades } \\
\hline Grade I (mild) & $60(25.5)$ & - \\
\hline Grade II (moderate) & $149(63.4)$ & - \\
\hline Grade III (severe) & $26(11.1)$ & - \\
\hline \multicolumn{3}{|c|}{$\begin{array}{l}\text { * SD: Standard Deviation } \\
\text { ** BMI: Body Mass Index, WHR: Waist to Hip Ratio, TC } \\
\text { Total Cholesterol, TG: Triglyceride, HDL-C: High- Density } \\
\text { Lipoprotein-Cholesterol, LDL-C: Low- Density Lipoprotein- } \\
\text { Cholesterol, DM: Diabetes Mellitus, NAFLD: Nonalcoholic } \\
\text { Fatty Liver Disease. }\end{array}$} \\
\hline
\end{tabular}

Table 2: The association between some factors affecting and NAFLD grades $(n=628)$

\begin{tabular}{|c|c|c|c|c|}
\hline \multirow[b]{2}{*}{ Variables } & \multicolumn{3}{|c|}{ NAFLD grades } & \multirow{2}{*}{$\begin{array}{l}P- \\
\text { Value* }\end{array}$} \\
\hline & $\begin{array}{l}\text { Grade } \quad I \\
(n=60)\end{array}$ & $\begin{array}{l}\text { Grade II } \\
(n=149)\end{array}$ & $\begin{array}{l}\text { Grade III } \\
(\mathrm{n}=26)\end{array}$ & \\
\hline Age & $54.5 \pm 5.8$ & $54.3 \pm 6.0$ & $54.3 \pm 5.9$ & 0.957 \\
\hline Gender & & & & 0.432 \\
\hline Male & $\begin{array}{l}40 / 146 \\
(27.4)\end{array}$ & $\begin{array}{l}88 / 146 \\
(60.3)\end{array}$ & $\begin{array}{l}18 / 146 \\
(12.3)\end{array}$ & \\
\hline Female & $\begin{array}{l}20 / 89 \\
(22.5)\end{array}$ & $\begin{array}{l}61 / 89 \\
(68.5)\end{array}$ & $\begin{array}{l}8 / 89 \\
(9.0)\end{array}$ & \\
\hline Race & & & & 0.974 \\
\hline Malay & $\begin{array}{l}12 / 47 \\
(25.5)\end{array}$ & $\begin{array}{l}31 / 47 \\
(66.0)\end{array}$ & $\begin{array}{l}4 / 47 \\
(8.5)\end{array}$ & \\
\hline Chinese & $\begin{array}{l}45 / 177 \\
(25.4)\end{array}$ & $\begin{array}{l}111 / 177 \\
(62.7)\end{array}$ & $\begin{array}{l}21 / 177 \\
(11.9)\end{array}$ & \\
\hline Indian & $\begin{array}{l}3 / 11 \\
(27.3)\end{array}$ & $\begin{array}{l}7 / 11 \\
(63.6)\end{array}$ & $\begin{array}{l}1 / 11 \\
(9.1)\end{array}$ & \\
\hline BMI & $25.6 \pm 3.1$ & $27.5 \pm 3.6$ & $29.7 \pm 4.6$ & $\begin{array}{l}< \\
0.001\end{array}$ \\
\hline WHR & $\begin{array}{l}0.93 \\
\pm 0.34\end{array}$ & $0.95 \pm 0.1$ & $0.97 \pm 0.1$ & $\begin{array}{l}< \\
0.001\end{array}$ \\
\hline \multicolumn{5}{|l|}{$\begin{array}{l}\text { Dietary } \\
\text { intake }\end{array}$} \\
\hline $\begin{array}{l}\text { Total calorie } \\
\text { intake per day } \\
(\text { Kcal/day)** }\end{array}$ & $\begin{array}{l}1862 \\
(1565- \\
2159)\end{array}$ & $\begin{array}{l}1852 \\
(1642- \\
2062)\end{array}$ & $\begin{array}{l}1462 \\
(1171- \\
1752)\end{array}$ & 0.297 \\
\hline $\begin{array}{l}\text { Protein intake } \\
\text { (Kcal/day) }\end{array}$ & $\begin{array}{l}92.4 \\
(76.7- \\
108.1)\end{array}$ & $\begin{array}{l}88.0 \\
(78.8- \\
97.2)\end{array}$ & $\begin{array}{l}79.7 \\
(60.3- \\
99.1)\end{array}$ & 0.635 \\
\hline $\begin{array}{l}\text { Fat intake } \\
\text { (Kcal/day) }\end{array}$ & $\begin{array}{l}1094.9 \\
(858.9- \\
1330.9)\end{array}$ & $\begin{array}{l}1129.2 \\
(959.4- \\
1299.0)\end{array}$ & $\begin{array}{l}820.7 \\
(610.4- \\
1030.9)\end{array}$ & 0.328 \\
\hline $\begin{array}{l}\text { Carbohydrate } \\
\text { intake } \\
\text { (Kcal/day) }\end{array}$ & $\begin{array}{l}675.5 \\
(570.4- \\
780.5)\end{array}$ & $\begin{array}{l}635.3 \\
(578.9- \\
691.7)\end{array}$ & $\begin{array}{l}561.9 \\
(441.1- \\
682.7)\end{array}$ & 0.403 \\
\hline $\begin{array}{l}\text { Physical } \\
\text { activity }\end{array}$ & & & & 0.311 \\
\hline Active & $\begin{array}{l}21 / 68 \\
(30.9)\end{array}$ & $\begin{array}{l}38 / 68 \\
(55.9)\end{array}$ & $\begin{array}{l}9 / 68 \\
(13.2)\end{array}$ & \\
\hline Inactive & $\begin{array}{l}39 / 167 \\
(23.4)\end{array}$ & $\begin{array}{l}111 / 167 \\
(66.5)\end{array}$ & $\begin{array}{l}17 / 167 \\
(10.2)\end{array}$ & \\
\hline \multicolumn{5}{|l|}{ Lipid profile } \\
\hline $\mathrm{TC}$ & $\begin{array}{l}5.71 \\
\pm 0.88\end{array}$ & $5.60 \pm 1.07$ & $\begin{array}{l}5.82 \\
\pm 0.98\end{array}$ & 0.541 \\
\hline TG & $\begin{array}{l}1.44 \\
\pm 0.49\end{array}$ & $1.71 \pm 0.73$ & $\begin{array}{l}2.46 \\
\pm 1.17\end{array}$ & $\begin{array}{l}< \\
0.001\end{array}$ \\
\hline HDL-C & $\begin{array}{l}1.40 \\
\pm 0.30\end{array}$ & $1.31 \pm 0.30$ & $\begin{array}{l}1.21 \\
\pm 0.21\end{array}$ & 0.016 \\
\hline LDL-C & $\begin{array}{l}3.65 \\
\pm 0.80\end{array}$ & $3.53 \pm 0.99$ & $\begin{array}{l}3.65 \\
\pm 0.91\end{array}$ & 0.651 \\
\hline DM & & & & 0.313 \\
\hline Present & $\begin{array}{l}4 / 26 \\
(15.4)\end{array}$ & $\begin{array}{l}20 / 26 \\
(76.9)\end{array}$ & $\begin{array}{l}2 / 26 \\
(7.7)\end{array}$ & \\
\hline Absent & $\begin{array}{l}56 / 209 \\
(26.8)\end{array}$ & $\begin{array}{l}129 / 209 \\
(61.7)\end{array}$ & $\begin{array}{l}24 / 209 \\
(11.5)\end{array}$ & \\
\hline Hypertension & & & & 0.553 \\
\hline Present & $\begin{array}{l}12 / 56 \\
(21.4)\end{array}$ & $\begin{array}{l}36 / 56 \\
(64.3)\end{array}$ & $\begin{array}{l}8 / 56 \\
(14.3)\end{array}$ & \\
\hline Absent & $\begin{array}{l}48 / 179 \\
(26.8)\end{array}$ & $\begin{array}{l}113 / 179 \\
(63.1)\end{array}$ & $\begin{array}{l}18 / 179 \\
(10.1)\end{array}$ & \\
\hline
\end{tabular}

\section{Discussion}

In our study, an overall prevalence of NAFLD has been reported in urban area to be $37.4 \%$. This was much higher than the prevalence rates reported in suburban area in Malaysia 21, and other Asia Pacific countries 22, which have ranged from $12-24 \%$. Our figure is consistent with another study carried out among urban subjects in Malaysia as the prevalence 
has been reported $49.6 \%$ 23. This indicates that prevalence of NAFLD is alarmingly high among urban population in Malaysia. Although, not truly a population-based study, we feel that our research on a large of "health screened" subjects grants us a fairly reliable indication of the burden of disease in a rural Malaysian population. In USA, NAFLD is also common, affecting up to $30 \%$ of the general population 24 . The present study revealed that more than half of our respondents had moderate NAFLD in the line with previous study by Cheah and his colleagues (2013) 25. On the other hand, the highest prevalence of mild NAFLD has been found among different ethnic groups in Malaysia whereas a moderate grade was the lowest 26. TC and HDL-C levels among subjects in our survey were above the normal values. These may be attributed to the higher prevalence and more severe grades of NAFLD in this study population. As such, genetic differences in this rural population may also be a contributing factor. A future study is recommended to do further justification for this.

Statistically, our findings demonstrated that the there was no significant association of age, gender and ethnicity with NAFLD grades. These findings are consistent with previous results by Krasnoff et al. 27 in California where they stated no differences of age and ethnic groups among the fatty liver grades. As expected, our study detected that BMI was significantly correlated with NAFLD grades where severity of NAFLD had progressively increase with BMI increases. Our results were inconsistent with a previous study by Sen et al. 28 which showed no significant association between BMI and hepatic steatosis grades. Nevertheless, Cheng et al. 29 confirmed a positive correlation between NAFLD severity and BMI.

Although WHR is used to define central obesity, there is no study that has addressed association between WHR and NAFLD grades. Otherwise, our study highlighted the correlation between WHR and NAFLD grades where NAFLD severity has increased with WHR increases, indicating the differences of WHR among NAFLD grades was documented. In the light of that, a recent study confirmed the significant differences of the WC among the steatosis grades 16 .

Moreover, calorie intake of protein, carbohydrate and fat were not associated with NAFLD grades and this finding is compatible with a previous study done by Chan et al.23 which confirmed no significant association between calorie intake of fat, carbohydrate and protein with NAFLD where cause is still unknown. Meanwhile, we also focused toward correlation of physical activity with NAFLD grades. Although previous studies confirmed association between physical activity and NAFLD grades 27 , our study did not revealed that and the cause may be attributed that most of our patients were physically inactive.

Regarding to lipid profile, this study is compatible with study by Sen et al.28 which confirmed that
NAFLD severity has increased with TG elevation whereas decreased with HDL-C reduces. In the other words, increase in TG levels and decrease in HDL-C levels lead to progress NAFLD to the advanced grades. Furthermore, both studies were also revealed that TC and LDL-C levels were not correlated with NAFLD grades. In the meantime, the association of DM and hypertension with NAFLD grades was not found to be significant in the present study, despite several studies identified that DM and hypertension are considered as risk factors for developing NAFLD. This explains that diabetes and hypertension induce fatty liver disease but not effect on its severity (grades).

Despite our effort, our study has several limitations correlated to the population sampling. The study population is, definitely, not reflective of the entire Malaysian population. In addition, the diagnosis of hepatic steatosis has been based on sonography and not histopathological examination of liver biopsy specimen, where the latter is more accurate to detect hepatic steatosis. The liver biopsy is invasive tool with some complications so that is not satisfactory in a study of this nature. Sonography is so far widely used to detect hepatic steatosis in both clinical and epidemiological studies. Although, ultrasound has a good sensetiuvity (89\%) and specificity (93\%) in diagnosis moderate and severe fatty liver, its sensitivity lacks in detecting mild fatty liver. Hence, underestimation of the true prevalence of NAFLD has been suspected as cases of mild fatty liver have been missed on sonography.

In summary, NAFLD is common among Malaysian adults in the urban population. The close association of NAFLD grades with BMI, WHR, TG and HDL-C has been well demonstrated.

\section{Acknowledgments}

The authors would like to acknowledge the help from Dr. Norafida Bahari/ radiologist from the Department of Imaging, Faculty of Medicine and Health Sciences, UPM. As well, thankful and grateful go to all of administrators and medical personnel who have willingly helped us out with their abilities in Golden Horses Health Sancturay, Klang Valley.

Authors' contributions:

Study conception: It was done by Abdul Sattar Arif Khammas, Rozi Mahmud and Safwan Saeed Mohammed.

Study design: The study was designed by Abdul Sattar Arif Khammas, Safwan Saeed Mohammed, Rozi Mahmud and Hasyma Abu Hassan

Acquisition of data analysis: It was done by Abdul Sattar Arif Khammas, Sarah Qahtan M. Salih, Ramlah Mohamad Ibrahim and Nurul Nadiah Mohamad Nasir

Interpretation of data: It was done by Abdul Sattar Arif Khammas, Rozi Mahmud, Hasyma Abu Hassan and Hayati kadir Shahar 
Drafting of manuscript: It was done by Abdul Sattar Arif Khammas, Rozi Mahmud, Safwan Saeed Mohammed, Sarah Qahtan M. Salih, Ramlah Mohamad Ibrahim and Nurul Nadiah Mohamad Nasir

Critical revision: It was done by Abdul Sattar Arif Khammas, Safwan Saeed Mohammed, Rozi Mahmud and Hasyma Abu Hassan

\section{References:}

1. Yu, J., Marsh, S., Hu, J., Feng, W., \& Wu, C. The pathogenesis of nonalcoholic fatty liver disease: interplay between diet, gut microbiota, and genetic background. Gastroenterology research and practice 2016; 2016:1-13

2. Neuschwander-Tetri, B. A. Non-alcoholic fatty liver disease. BMC medicine2017; 15: 1- 45.

3. Rinella, M. E. Nonalcoholic fatty liver disease: a systematic review. Jama2015; 313: 2263-2273.

4. Abu-Shanab, A., \& Quigley, E. MThe role of the gut microbiota in nonalcoholic fatty liver disease. Nature Reviews Gastroenterology and Hepatology2010; 7: 691-701.

5. Demir, M., Lang, S., \& Steffen, $H . \quad M$. Nonalcoholic fatty liver disease-current status and future directions. Journal of digestive diseases2015; 16: 541-557.

6. Tiniakos, D. G., Vos, M. B., \& Brunt, E. M. Nonalcoholic fatty liver disease: pathology and pathogenesis. Annual Review of Pathological Mechanical Disease2010; 5: 145-171.

7. Bacon, B. R., Farahvash, M. J., Janney, C. G., \& Neuschwander-Tetri, B. A. Nonalcoholic steatohepatitis: an expanded clinical entity. Gastroenterology1994; 107: 1103-1109.

8. Diehl, A., Goodman, Z., \& Ishak, K. Alcohollike liver disease in nonalcoholics: a clinical and histologic comparison with alcohol-induced liver injury. Gastroenterology1988; 95: 1056-1062.

9. Li, N., Zhang, G., Zhang, J., Jin, D., Li, Y., \& Liu, T. Non-alcoholic fatty liver disease is associated with progression of arterial stiffness. Nutrition, Metabolism and Cardiovascular Diseases2015; 25. 218-223.

10. Wah-Kheong, C., \& Khean-Lee, G. Epidemiology of a fast emerging disease in the AsiaPacific region: non-alcoholic fatty liver disease. Hepatology international2013; 7: 65-71.

11. Rampal, L., Rampal, S., Khor, G. L. et al. A national study on the prevalence of obesity among 16,127 Malaysians. Asia Pacific journal of clinical nutrition 2007; 16: 561-566.

12. Schwenzer, N. F., Springer, F., Schraml, C., Stefan, N., Machann, J., \& Schick, F. (2009). Noninvasive assessment and quantification of liver steatosis by ultrasound, computed tomography and magnetic resonance. Journal of hepatology2009;51: 433-445.

13. Farrell, G. C., Chitturi, S., Lau, G. K., \& Sollano, J. D. Guidelines for the assessment and management of non-alcoholic fatty liver disease in the Asia-Pacific region: Executive summary.
Journal of gastroenterology and hepatology2007; 22: 775-777.

14. Mottin, C. C., Moretto, M., Padoin, A. V. et al. The role of ultrasound in the diagnosis of hepatic steatosis in morbidly obese patients. Obesity surgery2004; 14: 635-637

15. Singh, D., Das, C. J \& ,Baruah, M. P. Imaging of non alcoholic fatty liver disease: A road less travelled. Indian journal of endocrinology and metabolism2013; 17: 990-995

16. Williamson, R., Perry, E., Glancy, S. et al. The use of ultrasound to diagnose hepatic steatosis in type 2 diabetes: Intra-and interobserver variability and comparison with magnetic resonance spectroscopy. Clinical Radiology2011; 66: 434-439. 17. Shahril, M. R., Sulaiman, S., Shaharudin, S. H., Isa, N., \& Hussain, S. Semi-quantitative food frequency questionnaire for assessment of energy, total fat, fatty acids, and vitamin A, $C$ and $E$ intake among malaysian women: Comparison with three days 24-hour diet recalls. Mal J Health Sci2008; 6: 75-91.

18. International Physical Activity Questionnaire (IPAQ) (2002). Short form IPAQ. (Online) www.ipaq.ki.se.

19. Booth, M. L., Ainsworth, B. E., Pratt, M. et al. International physical activity questionnaire: 12country reliability and validity. Med sci sports Exerc2003; 195: 3508-1381.

20. National Cholesterol Education Program (NCEP): Expert Panel on Detection, Evaluation and Treatment of High Blood Cholesterol in Adults (Adults Treatment Panel III) final report (2002). Circulation, 106, 3143

21. Goh, S., Ho, E. L., \& Goh, K. Prevalence and risk factors of non-alcoholic fatty liver disease in a multiracial suburban asian population in malaysia. Hepatology International2013; 7: 548-554.

22. Fan, J., Saibara, T., Chitturi, S., Kim, B. I., Sung, J. J., \& Chutaputti, A. What are the risk factors and settings for non-alcoholic fatty liver disease in Asia-Pacific? Journal of Gastroenterology and Hepatology2007; 22: 794800.

23. Chan, W., Tan, A. T., Vethakkan, S. R., Tah, P., Vijayananthan, A., \& Goh, K. Non-alcoholic fatty liver disease in diabetics-prevalence and predictive factors in a multiracial hospital clinic population in malaysia. Journal of Gastroenterology and Hepatology2013; 28: 1375-1383.

24. Cave M, Deaciuc I, Mendez C, et al. Nonalcoholic fatty liver disease: predisposing factors and the role of nutrition. J Nutr Biochemist 2007; 18: 184-95.

25. Cheah, W. L., Lee, P. Y., Chang, C. T., Mohamed, H. J., \& Wong, S. L. Prevalence of ultrasound diagnosed non-alcoholic fatty liver disease among rural indigenous community of Sarawak and its association with biochemical and anthropometric measures .Southeast Asian Journal of Tropical Medicine and Public Health2013; 44: 309-317 
26. Malik A, Cheah PL, Hilmi IN, Chan SP, Goh KL. Non-alcoholic fatty liver disease in Malaysia: A demographic, anthropometric, metabolic and histological study. Multiphase Pumping and Technologies Conference and Exhibition, 2007; 8: 58-64.

27. Krasnoff, J. B., Painter, P. L., Wallace, J. P., Bass, N. M., \& Merriman, R. B. Health-related fitness and physical activity in patients with nonalcoholic fatty liver disease. Hepatology2008; 47: 1158-1166.

28. Sen, A., Kumar, J., Misra, R. P., Uddin, M., \& Shukla, P. Lipid profile of patients having nonalcoholic fatty liver disease as per ultrasound findings in north indian population: A retrospective observational study. Journal of Medical \& Allied Sciences2013; 3: 59-62

29. Cheng, H., Wang, H., Chang, W. et al. Nonalcoholic fatty liver disease: Prevalence, influence on age and sex, and relationship with metabolic syndrome and insulin resistance. International Journal of Gerontology2013; 7: 194198. 